\title{
Alteration in Serum Lipid Profile Pattern in Oral Squamous Cell Carcinoma and Potentially Malignant Disorders
}

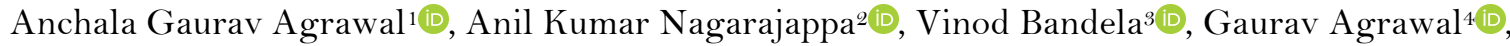 \\ Shailendra Singh Chaturvedi ${ }^{\circledR}$, Santosh R. Patil ${ }^{\oplus}$
}

\begin{abstract}
'Department of Oral Medicine and Radiology, Rural Dental College, Pravara Institute of Medical Sciences, Loni, India.
${ }^{2}$ Oral Radiology Division, Department of Oral and Maxillofacial Surgery and Diagnostic Sciences, College of Dentistry, Jouf University, Kingdom of Saudi Arabia.

${ }^{3}$ Department of Prosthetic Dental Sciences, College of Dentistry, Jouf University, Kingdom of Saudi Arabia.

${ }^{4}$ Department of Oral Pathology and Microbiology, Rural Dental College, Pravara Institute of Medical Sciences, Loni, India.

${ }^{5}$ Department of Periodontology, New Horizon Dental College and Research Institute, Bilaspur, India.

${ }^{6}$ Department of Oral Medicine and Radiology, New Horizon Dental College and Research Institute, Chhattisgarh, India.
\end{abstract}

Correspondence: Dr. Santosh R. Patil, Department of Oral Medicine and Radiology New Horizon Dental College and Research Institute, Chhattisgarh, India. E-mail: drpsantosh@,gmail.com

Academic Editor: Wilton Wilney Nascimento Padilha

Received: 30 April 2020 / Review: 28 December 2020 / Accepted: 15 January 2020

How to cite: Agrawal AG, Nagarajappa AK, Bandela V, Agrawal G, Chaturvedi SS, Patil SR. Alteration in serum lipid profile pattern in oral squamous cell carcinoma and potentially malignant disorders. Pesqui Bras Odontopediatria Clín Integr. 2021; 21 :e0083. https://doi.org/10.1590/pboci.2021.077

\begin{abstract}
Objective: To evaluate and compare lipid profile level in oral submucous fibrosis (OSMF), oral leukoplakia $(\mathrm{OL})$ and oral squamous cell carcinoma (OSCC) patients. Material and Methods: Thirty histopathologically diagnosed subjects each of OL, OSMF, OSCC were recruited along with 30 healthy controls. $5 \mathrm{ml}$ of venous blood is collected and estimated using standard diagnostic kits. Results: The mean of Total cholesterol level in controls was $219.03 \mathrm{mg} \%$, in OSCC, OL and OSMF was $142.89 \pm 10.21 \mathrm{mg} \%$, $155.44 \pm 17.63 \mathrm{mg} \%$ and $180.60 \pm 13.25 \mathrm{mg} \%$, respectively. The mean low-density lipid level in controls was $137.24 \mathrm{mg}$ and in OSCC, OL and OSMF groups were $109.28 \pm 2.16 \mathrm{mg} \%, 126.63 \pm 0.85 \mathrm{mg} \%$ and $119.15 \pm 0.93 \mathrm{mg} \%$, respectively. The mean of high-density lipid level in controls, OSCC, OL and OSMF was $42.87 \pm 0.42 \mathrm{mg} \%, 36.50 \pm 2.31 \mathrm{mg} \%, 21.13 \pm 0.77 \mathrm{mg} \%$ and $28.37 \pm 1.11 \mathrm{mg} \%$, respectively. The mean of very low density lipids level in controls, OSCC, OL and OSMF was $30.12 \pm 1.51 \mathrm{mg} \%, 17.24 \pm 0.80$ $\mathrm{mg} \%, 22.25 \pm 0.93 \mathrm{mg} \%$ and $25.89 \pm 0.43 \mathrm{mg} \%$, respectively. The mean triglyceride level in controls, OSCC, OL and OSMF was $118.80 \pm 9.47 \mathrm{mg} \%, 91.2 \pm 3.03 \mathrm{mg} \%, 105.05 \pm 2.96 \mathrm{mg} \%$ and $106.19 \pm 3.09$ $\mathrm{mg} \%$, respectively. Conclusion: Lipid profile levels could be early indicators of precancer and cancer.
\end{abstract}

Keywords: Pathology, Oral; Mouth Neoplasms; Oral Submucous Fibrosis; Carcinoma, Squamous Cell. 


\section{Introduction}

Cancer is one of the leading causes of adult death worldwide. Oral cancer is a serious problem in many countries [1]. Along with pharyngeal malignancy, oral cancer is regarded as the ninth most common cause of malignancy worldwide and the third major cause of mortality in developing countries [Q] . In India, oral cancer incidence is about 3 to 7 times more common compared to developed countries [3]. A high incidence of oral cancer (OC) is due to intense use of tobacco products. Therefore, cancer of the oral cavity is one of five leading sites of cancer in either sex [1]. A variety of tobacco habits are prevalent in India and they differ from region to region. The most widespread is the chewing of betel-quid with tobacco and this has been demonstrated as a major risk factor for cancers of the oral cavity.

Among all oral malignancies, the most common malignancy contributing to about $90 \%$ is oral squamous cell carcinoma (OSCC) [1]. Not only OSCC but also the use of tobacco and arecanut can also lead to potentially malignant disorders [2]. Oral cavity cancer is currently the most frequent cause of cancer related deaths among Indian men, which is usually preceded by oral potentially malignant disorders like oral leukoplakia $(\mathrm{OL})$ and/or oral submucous fibrosis (OSMF) [3]. Majority of the patients with potentially premalignant disorders are reported to be in 21-30 years of age group with a male to female ratio of 6.8:1 in India $[1]$.

Early detection is the key for oral cancer control and one of the major reasons behind the high mortality rate of oral cancer is the delay in early diagnosis of the potentially malignant disorders, the precursors of oral cancer. Oxidative stress has been considered a significant factor in the pathogenesis of numerous diseases and the antioxidant levels play a significant role in the pathogenesis and treatment of malignancies $[3,4]$. There are various biochemical markers available for precancer and cancerous patients, out of which one such tumor marker is serum lipid profile. Lipids are major cell membrane components essential for various biological functions, including cell growth and normal and malignant tissue division. The possible influence of lipids in the pathogenesis of malignancies could be attributable to influence on the metabolism of malignant cells in terms of proliferation and incorporation in the membranes of neoplastic cells and lipids' function intercellular messengers or as mediators of the inflammatory reaction [5].

An association of serum lipids and lipoproteins with different cancers has been reported [6]. Even though significant changes in blood cholesterol have been noted, the question whether hypolipidemia is a predisposing factor or a result of cancer still remains unanswered. In the present study, we evaluated the different biochemical lipid parameters such as total cholesterol (TC), triglyceride (TGL), high-density lipid (HDL), low-density lipid (LDL), very low-density lipid (VLDL) lipoprotein levels in OSMF, OL and OSCC. We also correlated the lipid profile parameters studied in OL, OSMF, OSCC and control groups.

\section{Material and Methods}

Study Design and Ethical Clearance

This study was planned and designed in the Department of Oral Medicine and Radiology, Hitkarini Dental College and Hospital, Jabalpur, Madhya Pradesh, India. This study was conducted over 2 years of duration and was approved by Institutional ethical committee (Protocol No. 18/032).

\section{Data Collection}

Thirty histopathologically diagnosed subjects each of OL, OSMF OSCC were recruited into the study and along with 30 healthy control subjects (without any oral habits), all recruited from patients attending 
outpatient department, Hitkarini Dental College and Hospital, Jabalpur, Madhya Pradesh, India. OSCC subjects were recruited from Department of General surgery, Netaji Subhash Chandra Bose Medical College and Hospital, Jabalpur, India. The subject's demographic data along with case history was recorded on a specially designed proforma. The study purpose and procedure were explained to the subjects and written informed consent was obtained. Patients with nephrotic syndrome, hyperthyroidism, diabetes mellitus, blood disorders, cardiovascular diseases were excluded from this study.

Serum Sample Collection, Storage, and Handling

About $5 \mathrm{ml}$ of blood samples were collected from venous arm puncture from each of the subjects. The sample was then kept in a plain sterile glass bulb and allowed to clot for 30-60 min at room temperature, followed by centrifugation at 3000 RPM for 10-15 min. Ice or cold packs were used to transport the serum specimen to the laboratory. The serum lipid profile activity was determined on the same day. The concentration of lipid parameters was estimated by using respective diagnostic kits (Cholesterol kit, Transasia Biomedicals Ltd., Daman, India) and a semiautomatic analyzer (CHEM-5 Plus V2, ERBA Diagnostics Mannheim GmbH, Germany). The protocols for the estimation of TC, TGL and HDL were followed as per the instruction available in the kit literature.

\section{Statistical Analysis}

The data was analyzed using IBM-SPSS software, version 22.0 (IBM Corp., Armonk, NY, USA). Shapiro-Wilk test showed that age, total cholesterol, triglycerides, VLDL, HDL and LDL follow normal distribution hence parametric test one-way ANOVA (analysis of variance) followed by LSD post hoc test was used for comparison between different groups. Gender distribution in different groups (nominal data) was compared using Pearson's chi-square test. The significance was tested at $5 \%$ level.

\section{Results}

Age and gender-wise distribution of study groups are represented in Tables 1 and 2 , respectively.

Table 1. Age distribution in study groups.

\begin{tabular}{|c|c|c|c|c|}
\hline \multirow[t]{2}{*}{ Groups } & \multirow[t]{2}{*}{ Mean } & \multirow[t]{2}{*}{ SD } & \multicolumn{2}{|c|}{ Age (Years) } \\
\hline & & & Minimum & Maximum \\
\hline Control & 50.70 & 9.19 & 29.00 & 65.00 \\
\hline Oral Squamous Cell Carcinoma & 50.97 & 9.18 & 32.00 & 65.00 \\
\hline Oral Leukoplakia & 46.17 & 10.26 & 25.00 & 62.00 \\
\hline Oral Submucous Fibrosis & 51.73 & 8.82 & 35.00 & 65.00 \\
\hline One-way ANOVA & \multicolumn{4}{|c|}{$\mathrm{F}=2.169, \mathrm{p}=0.095$} \\
\hline
\end{tabular}

Table 2. Gender-wise distribution of study groups.

\begin{tabular}{lccccc}
\multicolumn{1}{c}{ Groups } & \multicolumn{2}{c}{ Gender } & \multicolumn{2}{c}{ Female } & p-value \\
& N & $\%$ & N & $\%$ & \\
\hline Control & 27 & 90.0 & 3 & 10.0 & 0.147 \\
Oral Squamous Cell Carcinoma & 26 & 86.7 & 4 & 13.3 & \\
Oral Leukoplakia & 30 & 100.0 & 0 & 0.0 & \\
Oral Submucous Fibrosis & 29 & 96.7 & 1 & 3.3 & \\
\hline
\end{tabular}


The mean TC level in the control control group was $219.03 \mathrm{mg} \%$ with a standard deviation of \pm 11.00 $\mathrm{mg} \%$ in OSCC, OL and OSMF groups it was $142.89 \pm 10.21 \mathrm{mg} \%, 155.44 \pm 17.63 \mathrm{mg} \%$ and $180.60 \pm 13.25$ $\mathrm{mg} \%$ respectively (Table 3 ).

Table 3. Total Cholesterol levels in study groups.

\begin{tabular}{lcccc}
\multicolumn{1}{c}{ Groups } & \multicolumn{2}{c}{ Total Cholesterol (mg\%) } \\
& Mean & SD & Minimum & Maximum \\
\hline Control & 219.03 & 11.00 & 204.00 & 246.00 \\
Oral Squamous Cell Carcinoma & 142.89 & 10.21 & 130.60 & 160.00 \\
Oral Leukoplakia & 155.44 & 17.63 & 106.00 & 195.00 \\
Oral Submucous Fibrosis & 180.60 & 13.25 & 162.00 & 209.00 \\
One-way ANOVA & \multicolumn{3}{c}{$\mathrm{F}=190.155, \mathrm{p}<0.001$} \\
LSD Post Hoc Test & \multicolumn{3}{c}{ OSCC $<$ OL $<$ OSMF $<$ Control } \\
\hline
\end{tabular}

The mean of total LDL level in control group was $137.24 \pm 2.50 \mathrm{mg} \%$, in OSCC, OL and OSMF groups it was $109.28 \pm 2.16 \mathrm{mg} \%, 126.63 \pm 0.85 \mathrm{mg} \%$ and $119.15 \pm 0.93 \mathrm{mg} \%$, respectively (Table 4).

Table 4. Total LDL levels in study groups.

\begin{tabular}{lcccc}
\multicolumn{1}{c}{ Groups } & Mean & SD & Minimum & Maximum \\
\hline Control & 137.24 & 2.50 & 131.80 & 139.75 \\
Oral Squamous Cell Carcinoma & 109.28 & 2.16 & 107.60 & 114.80 \\
Oral Leukoplakia & 126.63 & 0.85 & 125.40 & 127.90 \\
Oral Submucous Fibrosis & 119.15 & 0.93 & 118.20 & 120.60 \\
One-way ANOVA & \multicolumn{2}{c}{$\mathrm{F}=1338.234, \mathrm{p}<0.001$} \\
LSD Post Hoc Test & \multicolumn{2}{c}{ OSCC $<$ OSMF $<$ OL $<$ Control } \\
\hline
\end{tabular}

Similarly, the mean of total HDL level in control group was $42.87 \pm 0.42 \mathrm{mg} \%$, in OSCC, OL and OSMF groups it was $36.50 \pm 2.31 \mathrm{mg} \%, 21.13 \pm 0.77 \mathrm{mg} \%$ and $28.37 \pm 1.11 \mathrm{mg} \%$, respectively (Table 5).

Table 5. Total HDL levels in study groups.

\begin{tabular}{lcccc}
\multicolumn{1}{c}{ Groups } & MDL $\mathbf{( m g \% )}$ \\
& Mean & Minimum & Maximum \\
\hline Control & 42.87 & 0.42 & 42.50 & 43.60 \\
Oral Squamous Cell Carcinoma & 36.50 & 2.31 & 35.23 & 48.20 \\
Oral Leukoplakia & 21.13 & 0.77 & 20.31 & 22.35 \\
Oral Submucous Fibrosis & 28.37 & 1.11 & 27.13 & 29.90 \\
One-way ANOVA & \multicolumn{3}{c}{$\mathrm{F}=1472.431, \mathrm{p}<0.001$} \\
LSD Post Hoc Test & \multicolumn{3}{c}{ Control $>$ OSCC $>$ OSMF $>$ OL } \\
\hline
\end{tabular}

The mean of total VLDL level in control group was $30.12 \pm 1.51 \mathrm{mg} \%$, in OSCC, OL and OSMF groups it was $17.24 \pm 0.80 \mathrm{mg} \%, 22.25 \pm 0.93 \mathrm{mg} \%$ and $25.89 \pm 0.43 \mathrm{mg} \%$, respectively (Table 6).

Table 6. Total VLDL levels in study groups.

\begin{tabular}{lcccc}
\multicolumn{1}{c}{ Groups } & \multicolumn{2}{c}{ VLDL $\mathbf{( m g \% )}$} & Minimum & Maximum \\
\hline Control & SD & 1.51 & 27.80 & 32.60 \\
Oral Squamous Cell Carcinoma & 17.24 & 0.80 & 16.50 & 18.70 \\
Oral Leukoplakia & 22.25 & 0.93 & 21.06 & 24.30
\end{tabular}




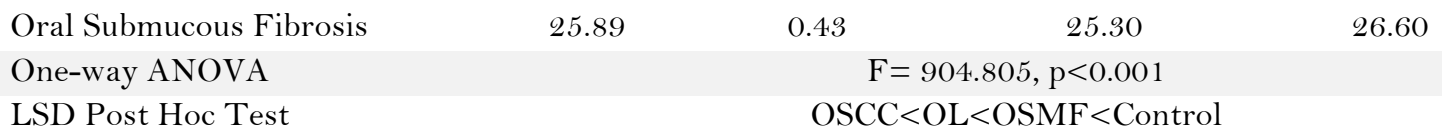

The mean of total TGL level in control group was $118.80 \pm 9.47 \mathrm{mg} \%$, in OSCC, OL and OSMF groups it was $91.2 \pm 3.03 \mathrm{mg} \%, 105.05 \pm 2.96 \mathrm{mg} \%, 106.19 \pm 3.09 \mathrm{mg} \%$, respectively (Table 7). One-way ANOVA test showed a statistically significant difference among the study groups with respect to TC, LDL, HDL, VLDL, and TGL levels $(\mathrm{p}<0.001)$.

Table 7. Total triglyceride levels in study groups.

\begin{tabular}{lcccc}
\multicolumn{1}{c}{ Groups } & Mean & SD & $\begin{array}{c}\text { Triglyceride }(\mathbf{m g} \%) \\
\text { Minimum }\end{array}$ & Maximum \\
\hline Control & 118.80 & 9.47 & 106.60 & 134.80 \\
Oral Squamous Cell Carcinoma & 91.02 & 3.03 & 87.00 & 99.00 \\
Oral Leukoplakia & 105.05 & 2.96 & 99.00 & 115.00 \\
Oral Submucous Fibrosis & 106.19 & 3.09 & 101.00 & 118.00 \\
One-way ANOVA & & $\mathrm{F}=131.992, \mathrm{p}<0.001$ & \\
LSD Post Hoc Test & \multicolumn{2}{c}{ OSCC $<$ OL $=$ OSMF $<$ Control } \\
\hline
\end{tabular}

\section{Discussion}

Head and neck cancer is one of the leading causes of morbidity and mortality with metastatic and invasive ability [7,8]. The habit of tobacco consumption is a known etiological factor. In malignant diseases, the blood cholesterol undergoes early and significant changes. Low levels of cholesterol in the proliferating tissues could be due to the process of carcinogenesis. However, the hypocholesterolemia that prevails is due to the cancer effects or is a cause for cancer occurrence yet to be answered [8].

Several explanations of the inverse associations between low serum cholesterol and cancer have been proposed and there may be a direct causal link between low cholesterol and cancer [9].

The reduced lipid profile may also be due to greater utilization of lipids for new membrane biogenesis, cells fulfill these requirements from circulation by synthesis through metabolism or from degradation of major lipoprotein fractions like HDL, LDL and VLDL [8].

There are three main competing hypotheses to explain this inverse association. First, lower cholesterol values, even before the manifestation or detection of cancer, may be a result of the cancer process; second, lower cholesterol values may precede the development of cancer, but the association with cancer is secondary, which indicates that cholesterol serves as a marker for some other causal variable or set of variables; third, lower cholesterol values may precede the development of cancer and may be causally associated with the occurrence of some forms of cancer [10].

Kark et al. [7] and Ray et al. [11] concluded that TC was found at significantly lower levels in oral cancer patients compared with controls of comparable age and sex distribution. Patel et al. [12] reported a decrease in plasma TC, HDL, VLDL, TGL levels in patients with oral malignancy as well as in patients with oral precancerous conditions as compared to the controls. The tobacco habituates showed lower plasma lipid levels than the non-habituates. Result of their study correlates with the result of the present study [12]. Similarly, Gupta and Gupta [13] observed a significant decrease in plasma total cholesterol, HDL, TC, and TGL in the patients with precancerous lesions and conditions, Singh et al. [14], reported a significant decrease in TC, HDLC and TGL in the oral cancer group. Kumar et al. [15] and Kanthem and Guttikonda [16] found 
significantly decreased lipid levels in OSMF patients, Neerupakam et al. [17] noted a significant decrease in the total cholesterol and HDL in oral cancer subjects, which was similar to the results of our study.

Lohe et al. [18] evaluated cholesterol levels in patients with precancer and oral carcinoma and a significant decrease in TC, HDL, VLDL and TGL was noted in later patients. Mehrotra et al. [19] noticed a significant decrease in plasma HDLC and Apo-A1 in patients with OSMF compared to the controls in accordance with the present study. In this study, authors found a significant increase in TC, LDL, VLDL and TGL levels, which were not similar with the present study [19].

\section{Conclusion}

In the present study, the serum profiles were reduced in OSCC, OL, and OSMF subjects compared to healthy controls. Our study supports the fact that lipid profile levels can be used as a diagnostic parameter in detecting precancer and cancer early. The reduced lipid profile is of clinical beneficence to assess the prognosis of the patients and predict the survival rate in cases of OL, OSMF. Perhaps they could also be used to predict the malignant transformation.

\section{Authors' Contributions}

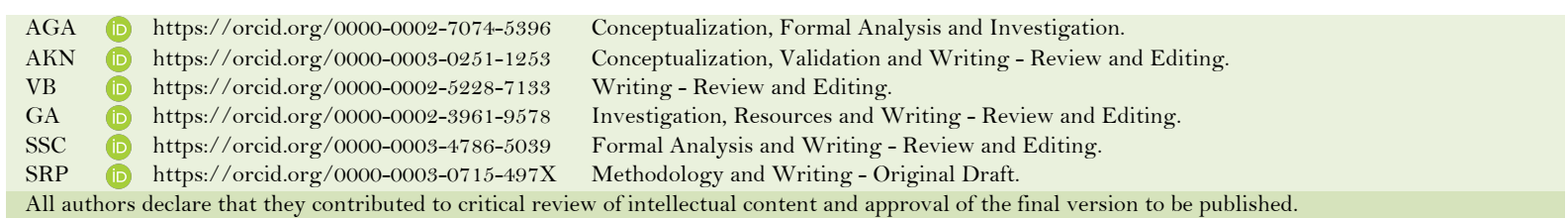

\section{Financial Support}

None.

\section{Conflict of Interest}

The authors declare no conflicts of interest.

\section{Data Availability}

The data used to support the findings of this study can be made available upon request to the corresponding author.

\section{References}

[1] Srivastava KC. Saliva's oxidant-antioxidant profile in oral cancer. Int J Med Dent 2019; 23(2):215-22.

[Q] Srivastava KC. Comparative evaluation of saliva's oxidant-antioxidant status in patients with different clinicopathological types of oral leukoplakia. J Int Soc Prev Community Dent 2019; 9(4):396-402. https://doi.org/10.4103/jispcd.JISPCD_179_19

[3] Srivastava KC, Shrivastava D. Analysis of plasma lipid peroxidation and antioxidant enzymes status in patients of oral leukoplakia: a case control study. J Int Soc Prev Community Dent 2016; 6(Suppl 3):S213-S218. https://doi.org/10.4103/2231-0762.197195

[4] Ghaedi E, Rahrovani F, Javanbakht MH, Ehsani AH, Esrafili A, Mohammadi H, et al. Retinol and $\alpha$-tocopherol levels in the serum and subcutaneous adipose tissue of newly diagnosed basal cell carcinoma patients. Iran J Public Health $2019 ; 48(10): 1838-46$.

[5] Rahrovani F, Javanbakht MH, Ehsani AH, Esrafili A, Mohammadi H, Ghaedi E, et al. Erythrocyte membrane saturated fatty acids profile in newly diagnosed basal cell carcinoma patients. Clin Nutr ESPEN 2018; 23:107-11. https://doi.org/10.1016/j.clnesp.2017.11.007

[6] Scully C, Bagan JV, Hopper C, Epstein JB. Oral cancer: current and future diagnostic techniques. Am J Dent 2008; 21(4):199-209.

[7] Kark JD, Smith AH, Hames CG. Serum retinol and the inverse relationship between serum cholesterol and cancer. Br Med J 1982; 284(6310):152-4. https://doi.org/10.1136/bmj.284.6310.152 
[8] Peterson C, Vitols S, Rudling M, Blomgren H, Edsmyr F, Skoog L. Hypocholesterolemia in cancer patients may be caused by elevated LDL receptor activities in malignant cells. Med Oncol Tumor Pharmacother 1985; 2(3):143-7. https://doi.org/10.1007/BF02934541

[9] Eichholzer M, Stähelin HB, Gutzwiller F, Lüdin E, Bernasconi F. Association of low plasma cholesterol with mortality for cancer at various sites in men: 17-y follow-up of the prospective Basel study. Am J Clin Nutr 2000; 71(2):569-74. https://doi.org/10.1093/ajcn/71.2.569

[10] Reddy AV, Killampalli LK, Prakash AR, Naag S, Sreenath G, Biraggari SK. Analysis of lipid profile in cancer patients, smokers, and nonsmokers. Dent Res J 2016; 13(6):494-9. https://doi.org/10.4103/1735-3327.197036

[11] Ray A, Dayalu Naik SL, Bahadur AK, Pasha ST, Rautela RS, Sharma BK. Serum lipids, lipoproteins and sex-hormone binding globulin in breast cancer. Indian J Clin Biochem 2001; 16(1):101-5. https://doi.org/10.1007/BFo2867576

[12] Patel PS, Shah MH, Jha FP, Raval GN, Rawal RM, Patel MM, et al. Alterations in plasma lipid profile patterns in head and neck cancer and oral precancerous conditions. Indian J Cancer 2004; 41(1):25-31.

[13] Gupta S, Gupta S. Alterations in serum lipid profile patterns in oral cancer and oral precancerous lesions and conditions - a clinical study. Indian J Dent 2011; 2(2):1-7. https://doi.org/10.1016/So975-962X(11)60002-6

[14] Singh S, Ramesh V, Premalatha B, Prashad KV, Ramadoss K. Alterations in serum lipid profile patterns in oral cancer. J Nat Sci Biol Med 2013; 4(2):374-8. https://doi.org/10.4103/0976-9668.116994

[15] Kumar P, Singh A, Sankhla B, Naraniya A. Alteration in plasma lipid profile in oral submucous fibrosis patients: A case control study. South Asian J Cancer 2013; 2(3):147-9. https://doi.org/10.4103/2278-330X.114134

[16] Kanthem RK, Guttikonda VR. Serum lipid profile in oral submucous fibrosis: A clinico pathological study. J Oral Maxillofac Pathol 2015; 19(2):139-44. https://doi.org/10.4103/0973-029X.164522

[17] Neerupakam M, Alaparthi RK, Sathish S, Katta SA, Polisetty N, Damera S. Alterations in plasma lipid profile patterns in oral cancer. J Indian Acad Oral Med Radiol 2014; 26(3):274-8.

[18] Lohe VK, Degwekar SS, Bhowate RR, Kadu RP, Dangore SB. Evaluation of correlation of serum lipid profile in patients with oral cancer and precancer and its association with tobacco abuse. J Oral Pathol Med 2010; 39(2):141-8. https://doi.org/10.1111/j.1600-0714.2009.00828.x

[19] Mehrotra R, Pandya S, Chaudhary AK, Singh HP, Jaiswal RK, Singh M, et al. Lipid profile in oral submucous fibrosis. Lipids Health Dis 2009; 8:29. https://doi.org/10.1186/1476-511X-8-29 